\title{
AUTOMOTIVE MARKET- FROM A GENERAL TO A MARKET SEGMENTATION APPROACH
}

\author{
Liviana Andreea Niminet \\ "Vasile Alecsandri" University of Bacău \\ liviana.niminet@ub.ro
}

\begin{abstract}
Automotive market and its corresponding industry are undoubtedly of outmost importance and therefore proper market segmentation is crucial for market players, potential competitors and customers as well. Time has proved that market economic analysis often shown flaws in determining the relevant market, by using solely or mainly the geographic aspect and disregarding the importance of segments on the automotive market. For these reasons we propose a new approach of the automotive market proving the importance of proper market segmentation and defining the strategic groups within the automotive market.
\end{abstract}

Keywords

automotive markets; market analysis; market segmentation; strategic groups

JEL Classification

L62; L53; L26

\section{Introduction}

Nowadays Automotive market analysis is facing an important short come determined by the fact that all the official statistics on automotive market are based on the same wholesales within a determined market criterion. This means that the criterion is the automotive market of a country, a region or a group of countries (such as the European Union). Officials consider that the automotive market can be defined solely by country or by region and in their understanding this approach is sufficient for comprehension of market size analysis.

However we can easily see that this is a questionable approach as it does not take into account important aspects and leads people reading the statistics believe, for instance, that automotive like Dacia Logan and Volkswagen Passat are competing on the same market only because they are sold on the same country, or in the same group of countries. In APIA, ACEA or even European Union understanding the relevant market of automotives comes down to the products sold: automotives and the geographical dimensions of the market: country/group of countries.

\section{Market segmentation}

As we stated earlier we cannot accept such a general approach because it misses a lot of the outmost important aspects. Consider that a collection of markets compose an industry. The automotive industry is composed by the new and used car markets and the aftermarket for spare parts. Furthermore, markets can be subdivided by model, year or by makes and each subdivision either by product or by geographic area defines a new market in the automotive industry.

The automotive market has changed. The time of "Give the customer any color of car they want, so long it is black" (Ford) has passed. This perspective worked for the time when customers just wanted a car, any car. More and more the perspective turned into the car that fit different "purpose, purse and personality" (GM). If in the early days of 
the automotive market customers main interest was to have a car as time went by their needs began to change, and customers started to focus on a car's characteristics rather than solely on the functional aspect. There appeared cars for the rich, for the medium class, city cars, off road cars, speed cars, shopping cars and so on.

Together with the developing of the automotive market and highly differentiated products that meet different forms of needs and expectations it became obvious that market analysis needed change. This was one of the main reasons that brought into attention the concept of market segmentation. But what does a market segment mean? The segment of the market is about products sold on the market or is about the customers from the market? The first impulse would be to say that market segmentation is "definitely about the products", but on a closer look one can realize that in fact a segment is "a group of people".

Philip Kotler proved that "market segmentation is subdividing a market into distinct and homogenous subgroups of customers where any group can conceivably be selected as a target market...”. Market segmentation is therefore a method of "dividing the market into smaller groups of customers or organizations in which each segment has a common characteristic such as needs or behavior". Following this reasoning we can identify different types of market segmentation.

- Benefit segmentation mean a group of people who share and seek for similar benefits. This segment is thus about needs and satisfaction of these needs

- Demographic segmentation means a group of people who share similar gender, age, income, occupation, education, and so on. Applying this segmentation one can identify cars for the rich or for the youth, "gents only" and the list can go on.

- Lifestyle segmentation supposes a group of people who may share the same lifestyle and thus orient to the same type of automotive.

Fact of the matter is that only market segmentation can help dividing the market actors into strategic groups. As we stated above, segmentation analysis traditionally focuses on products characteristics of product markets as a fundament for dividing industries. Furthermore, the strategic group analysis uses firm's characteristics and the nature of competition intensity varies.

\section{Strategic groups and "traditional" type of automotive market segmentation}

So a new question arises: who does industry segmentation help? Well, industry segmentation is very useful both for new market entrants as well as for the existing firms helping them to decide resources allocation and also which segments to maintain.

Strategic groups are clusters of firms that have common characteristics and follow the same or similar strategies in setting key decision variables:

$>$ Product market scope

$>$ Distribution channels' choice

$>$ The level of the quality of the product

$>$ The degree of the vertical integration

$>$ The choice of the technology.

Putting it simple, the strategic group is the middle ground between industry and firm. There are industries with obvious group structure and with a high degree of homogeneity and there are also industries in which exist differences considering the strategies that firms use. The down side is that strategic groups do not offer any information regarding the profitability of the firm, but offer a complete image of the types of firms in a given industry. 
Regarding the automotive sector, there are several ways for segmentation this particular market. One of the most used segmentation proposes a combination of price and size of the automotives. It was developed by the United Kingdom motor industry trade association (SMMT) and is generally accepted by the industry. It proposes 9 segments for the automotive market, depending mainly on vehicle size:



Time evolution analysis prove that class B and C (small and lower-medium cars) on most of the markets sum up to $30 \%$ wholesales market share. Strategic groups are determined on the base of diversification of product lines. From this perspective we can identify:

- $\quad$ Niche producers

- $\quad$ Broad line producers

Diversification criteria suppose the degree of companies' products dispersion across the segments. However, measuring these criteria is extremely difficult. Although the easiest way may seem counting the number of segments, this can be proved quite inadequate because it does not reflect the importance of each segment.

For a better understanding, let us take the case of Mercedes. Mercedes is present on three of the above considered segments and still over $90 \%$ of the producers' sales are on the Executive segment E. So, we could use a measure that takes into account the amount of the corresponding sales for each of the segments.

$$
\text { Propose an Index }=\sqrt{\sum_{i=1}^{N} S_{i}{ }^{2}}
$$

Where $\mathrm{N}$ is the number of segments; And $\mathrm{S}$ is the percentage share of the segment. It squares market shares individually while the square root is taken of the total).

This mean that a player that operates in only one segment, also called niche player will receive an Index that is equal with 100 and the firms that are present in an indefinite number of segments will get an unitary Index .

On a close look we can see that the summation part of the proposed index is the same that we used to calculate the degree of concentration. In another words, this means that the Index is a different use of Hirschman-Herfindal Index. The square root was used as to avoid the HHI exponential character.

We can thus identify:

$>$ diversified low end producers: Nissan, Fiat, Ford, Renault;

$>$ Diversified high end producers: BMW, Mazda, Toyota, Volkswagen

$>$ Specialized medium producers: Honda

$>$ Specialized High End producers: Mercedes, Volvo.

Companies that are on the same strategic group tend to focus on the same primary segment and cross over the segments. For instance BMW and Volkswagen are likely to compete in most of their market segments. We cannot but observe that any analysis regarding strategic groups impose the use of caution. This is because the automotive industry is extremely competitive and evens the firms that seem much distanced from each other are likely to compete in some way. 
Market segmentation proposes:

1. New automotive

2. Used automotive

Regarding the manufacturer there are:

- Home automotives

- Imported automotives

Depending on the purpose of the automotive there are:

- Fleet

- Business

- Private

Considering the brand on the automotive market of Romania there are:

- Dacia

- Fiat,

- Ford

- Mercedes

- Skoda and so on

\section{New perspective on automotive market segmentation}

A study developed in France identified on the automotive market a more customer adjusted segmentation. The segmentation proposed is dependent on the psychological attitudes of the consumer. Thus it identifies three types of automotive customer:

1. The functional automotive buyers. This segment considers automotive an instrument that satisfy the need of free movement

2. Sportive automotive buyers are the ones that need not only a car but a fast, performing car to feed up their adrenaline need.

3. Social automotive buyers. For this segment the social dimension of purchasing a car is the most important.

But what makes market segmentation so important? Why can't we consider the whole market as individuality rather than a sum of segments? Well, the answer is quite simple and comes from the hear-say wisdom: "it is better to be a big fish in a small pond, than a small fish in a big pond". This could be translated in the fact that for being a "big fish" a firm should shrink its target market and specialize on a particular sort of customer by narrowing the target, by market segmentation, thus.

If now it is clear that market segmentation is vital both for firms and for the consumers, we should consider a method for identifying correctly the market segments. For this it is important to highlight the features that a market segment should have:

$>$ Different

$>$ Significant

$>$ Relevant

$>$ Accessible

$>$ Size suitable.

Let us see each and every aspect above on a closer approach.

Difference refers to a number of things: the geographic difference, the industry and the consumer interest. If we are dealing with a horizontal market we identify the geographical segment while in the case of a vertical market we have a industry market. So, the ways for defining the segments are: the size of the company and price brackets.

Relevance and significance refers to something special about the needs of the segment. For instance companies need cheap cars with low consumption and low 
maintenance costs; families need comfortable, safe cars; youth needs cars that "make a statement"

Accessibility refers to the "community" of the segment. The community means the social clubs, on-line forums, magazines and journals. Dacia for instance has a Club, a Forum dedicated and the producer also edits journals regarding the brand. All these are very important because the community, the members of the segments allow the best for of market possible that is the "word of mouth".

Last but not least, the Size of the segment. The purpose of a segment, any segment is to become a major player on the automotive market, this means to have at least $25 \%$ percent of the market. But which is the ideal, best size of the segment for a firm? Well, the ideal size of the segment is there up to ten times your target turnover. If it is smaller than that it wouldn't allow you to growth, and if it is a lot bigger, one would be not the leader but only one of the bit players.

\section{Conclusions}

As we proved the official manner used by national and international organisms and automotive associations for segmenting the automotive market are based on wholesales within a geographical market. This approach is quite improper and often determines miss judgment. For these reasons we proposed another type of market segmentation based on the realities of the automotive markets and customers expectations. This type of automotive market segmentation accomplishes the request of taking into account the important differences between market players and allows a correct view on the market structure.

\section{References}

Czinkota, M.R., Ronkainen, I.A., Donath, B (2004), Mastering Global Markets: Strategies for Today's Trade Globalist, South-Western, Mason, $\mathrm{OH}$,

Johnson, B. and Lilien, G.L. (1994), A Framework and Procedure for Assessin Market Segment Change, Penn State ISBM Working Paper, Penn State University,University Park, PA Author

Kotler, P., Keller, K.L. (2005), Marketing, Management, Prentice Hall, Englewood Cliffs, $\mathrm{NH}$

Nimineţ, L.A. (2013), The automotive market-an ongoing turmoil, Procedia Economics and Finance (Elsevier) forthcoming November 2013.

Reutterer, T., Mild, A., Natter, M., Taudes A. (2006), A dynamic segmentation approach for targeting and customizing direct marketing campaigns, Journal of Interactive Marketing, 20(3/4), 43-52 .

Yankelovich, D., Meer, D. (2006), Rediscovering market segmentation, Harvard Business Review , 84(2), 122-132.

Wind Y., Bell, D.R. (2007), Market segmentation, in Marketing book, 230-266, PW. 